\title{
スパッタリングガスイオンが薄膜特性に及ばす影響
}

\author{
宮田隼平 $1, * \quad$ 豊田椋 $-1, * \quad$ 橋本真希 $1, *$ \\ 飯島貴 朗 2 ** 利根川 昭 ${ }^{3} \quad$ 松 村義 人 $^{1}$
}

\author{
1東海大学大学院工学研究科応用理学専攻 \\ 2 東海大学大学院総合理工学研究科総合理工学専攻 \\ 3 東海大学理学部物理学科
}

J. Japan Inst. Met. Mater. Vol. 80, No. 4 (2016), pp. 280-283

(C) 2016 The Japan Institute of Metals and Materials

\section{Effect of Sputtering Gas Ions on Thin Film Properties}

\author{
Shumpei Miyata ${ }^{1, *}$, Ryoichi Toyoda ${ }^{1, *}$, Maki Hashimoto, ${ }^{1, *}$, \\ Takaaki Iijima ${ }^{2, *}$, Akira Tonegawa ${ }^{3}$ and Yoshihito Matsumura ${ }^{1}$ \\ ${ }^{1}$ Tokai University, Course of applied science, Graduate school of engineering, Hiratsuka 259-1292 \\ ${ }^{2}$ Tokai University, Graduate School of Science and Technology, Hiratsuka 259-1292 \\ ${ }^{3}$ Tokai University, Department of Physics, School of Science, Hiratsuka 259-1292
}

\begin{abstract}
In thin films that are prepared by sputtering, internal stress is generated during film formation. Internal stress is widely known to induce substantial changes in the properties of thin films, including their mechanical and optical properties and electromagnetic characteristics. The internal stress of sputtered films, which is generated by changes in their sputtering powers and gas pressures and substrate biases, is affected by ion bombardment during thin-film deposition. In our recent research, we studied methods of measuring the ion energy in the plasma and sheath regions using a multigrid electrostatic ion analyzer and a Langmuir probe. The obtained data suggested that the effect of ion bombardment can be quantitatively evaluated. In the present study, sputtered thin films were deposited using different sputtering gases and varying substrate biases. We attempted to control the internal stress of the deposited thin films by evaluating the ionic bombardment during film deposition as ion-bombardment parameter $P_{\mathrm{i}}$, which was affected by the sputtering gas ions. The results demonstrate that the internal stress of the thin films decreased with increasing the ion-bombardment parameter $P_{\mathrm{i}}$. The compressive stress was increased by the peening effect of the sputtering gas ions. Therefore, evaluating the internal stress of thin films using the ion-bombardment parameter $P_{\mathrm{i}}$ is feasible. [doi:10.2320/jinstmet.JBW201504]
\end{abstract}

(Received October 14, 2015; Accepted December 11, 2015; Published February 5, 2016)

Keywords: sputtering, ion bombardment, internal stress, substrate bias, multi-grid electro-static ion analyzer, Langmuir probe, plasma

\section{1. 緒言}

薄膜作製において成膜中に生じた内部応力が，薄膜の機械 的 ·光学的 ·電磁気的特性といった薄膜特性を大きく変化さ せることが知られている1-3). スパッタ薄膜の内部応力はス パッタリングガスイオン(以降イオン)のイオン衝撃の影響を 受け，そのイオン衝撃は成膜中のスパッタリング電力・スパ ッタリングガス圧, 基板バイアスなどにより変化することが 知られている. 近年ではスパッタ成膜中の薄膜堆積中のイオ ン入射に打けるイオン衝撃により, 薄膜特性を制御しようと 試みられている ${ }^{4-6)}$. Hoffman らは, 薄膜に入射するイオン によるイオン衝撃が薄膜の内部応力に及ぼす影響に関して, イオンの入射頻度と堆積粒子の入射頻度の比に依存すること を報告しており，またWindishmann らは，スパッタ薄膜の 内部応力はイオンのエネルギーに依存していることを報告し

* 東海大学大学院生 (Graduate student, Tokai University)
ている7-11).これまで我々は, 成膜時のスパッタ電力を変化 させイオンと堆積粒子の入射頻度が変化した際に, 原子量の 異なるイオンが薄膜の内部応力に及ぼすイオン衝撃の影響を イオン衝撃パラメータ $P_{\mathrm{i}}$ により評価を行い定量的に評価す ることが可能であると明らかにしてきた ${ }^{12)}$. そこで, 本研 究では基板バイアスを変化させイオンの運動量が変化した際 に, 原子量の異なるスパッタリングガス $(\mathrm{Ar}$ : 原子量 40 , $\mathrm{Xe}$ : 原子量 131) が薄膜の内部応力に及ぼすイオン衝撃を $P_{\mathrm{i}}$ により評価を行った．また，より精密なプラズマ診断を行う ため, マルチグリッド型静電イオンアナライザー(MGA) と 平板型ラングミュアプローブの二つを用いて測定を行った.

\section{2. 実 験 方 法}

\section{1 薄膜作成方法}

本研究には, プレーナー型直流放電マグネトロンスパッタ リング法を用い，スパッタリングターゲットには純度 99.9 $\operatorname{mass} \%$, 直径 $75 \mathrm{~mm}$, 厚さ $3 \mathrm{~mm}$ の $\mathrm{Ni}$ を用い, 基板には $\mathrm{n}$ 
型単結晶 $\mathrm{Si}(100)(4.7 \mathrm{~mm} \times 24.7 \mathrm{~mm} \times 0.3 \mathrm{~mm})$ 上に堆積さ せた。スパッタリングガスには $\operatorname{Ar}(99.999 \mathrm{vol} \%$ ) (質量数 40)と Xe (99.995 vol\%) (質量数 131)をそれぞれ用い，スパ ッタリングガス同士の衝突によるエネルギー減少を防ぐた め, イオンの平均自由行程が基板ーターゲット間距離の 80 $\mathrm{mm}$ 以上になるように，それぞれのスパッタリングガスの圧 力を調整した. 到達真空度は $1.0 \times 10^{-4} \mathrm{~Pa}$ 以下とし， スパ ッタ中の真空度は Bayer-Alpert 型電離真空計の直読值で $\mathrm{Ar}$ については $9.3 \times 10^{-2} \mathrm{~Pa}$, Xe については $1.3 \times 10^{-1} \mathrm{~Pa}$ と し, 希ガスを導入後, ターゲット清浄化のためプレスパッタ を行った．スパッタ電力は $30 \mathrm{~W} て ゙$ 基板バイアスを $-30 \mathrm{~V}$ からー120 V までの任意の值で成膜を行った。熱応力による 影響を一定にするため, 基板温度は $380 \pm 5 \mathrm{~K}$ とし，薄膜の 厚さが約 $1 \mu \mathrm{m}$ になるように薄膜作製を行った．作製した薄 膜の膜厚は触針式表面形状測定器 (Sloan DectakIII)を用い て測定した

\section{2 プラズマ診断}

本研究ではプラズマ診断に MGA ならびに，シングルラン グミュアプローブを用いて測定を行った．Fig. 1 に測定に用 いた MGAの模式図を示す，MGA は，前面のグリッド 1 (G1)には負電圧をかけ，電子を阻止することによりイオン のみが入射する。そこで，グリッド $2(\mathrm{G} 2)$ の電位を変化さ せ，G2の電位を超えてきたイオンのみがコレクタ一電極に 入射する. $\mathrm{G} 2$ の電位は $-40 \mathrm{~V}$ から $+40 \mathrm{~V}$ 間で電圧を変化 させた。コレクター電極 $(\mathrm{C})$ に G19電位より深い電圧を印 加することで，イオンが Cに引き込まれ電流が発生する. イオン入射量は本実験で用いたスパッタ中の真空度におい て，スパッタガスイオンの生成量がスパッタされたターゲッ トのイオンの生成量を大きく上回るため, スパッタされた ターゲットのイオンが入射する数はわずかである13)。その ことから，MGAにより計測されるイオンの入射量はスパッ タリングガスイオンの入射量とみなし，このときの G 2 に印 加された電圧に対し C で計測される電流(電圧電流特性)の 傾きから, 素電荷 $e=1.60 \times 10^{-19} \mathrm{C}$, ボルッマン定数 $k_{\mathrm{b}}=$ $1.38 \times 10^{-23} \mathrm{~J} / \mathrm{K}$ を用いてイオンの温度 $T_{\mathrm{i}}$ を次式より導出 した.

$$
T_{\mathrm{i}}=\frac{e}{k_{\mathrm{b}}} \cdot \frac{1}{d \log I / d V_{\mathrm{A}}}
$$

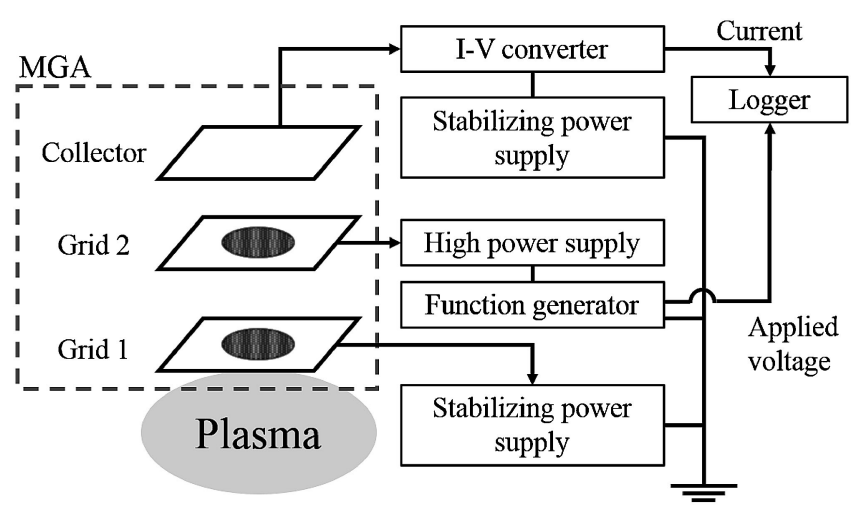

Fig. 1 Diagram of Multi grid analyzer (MGA).
プラズマ中に打けるイオンの熱速度 $v_{\text {th }}$ を, 式 (1)より求 めたイオンの温度 $T_{\mathrm{i}}$ と, イオンの質量 $m_{\mathrm{i}}$, ボルツマン定数 $k_{\mathrm{b}}$ を用いて次式から導出した.

$$
v_{\mathrm{th}}=\sqrt{\frac{3 k_{\mathrm{b}} T_{\mathrm{i}}}{m_{\mathrm{i}}}}
$$

Fig. 2 に測定に使用したラングミュアプローブの模式図を 示した. ラングミュアプローブ法では，ステンレス製の平面 板プローブを用い， $-40 \mathrm{~V}$ から $+40 \mathrm{~V}$ 間で電圧を変化させ た。また，ラングミュアプローブ法により計測された電圧電 流特性の変曲点をプラズマ電位 $V_{\mathrm{s}}$ とした. シース領域での イオンの速度 $v_{\mathrm{sh}}$ を，ラングミュアプローブ法より得られた プラズマ電位 $V_{\mathrm{s}}$ と基板電位 $V_{\mathrm{sub}}$ 間 (シース領域)での電位 差, 素電荷 $e$, イオンの質量 $m_{\mathrm{i}}$ から次式を用いて導出した.

$$
v_{\mathrm{sh}}=\sqrt{\frac{2 e\left|V_{\mathrm{s}}-V_{\mathrm{sub}}\right|}{m_{\mathrm{i}}}}
$$

また， $v_{\mathrm{th}}$ および $v_{\mathrm{sh}}$ より基板に入射するイオンの自乗平均 速度を速度 $\bar{v}_{\mathrm{i}}\left(\mathrm{m} \cdot \mathrm{s}^{-1}\right)$ として次式より算出した。

$$
\bar{v}_{\mathrm{i}}=\sqrt{v_{\mathrm{th}^{2}}+v_{\mathrm{sh}^{2}}}
$$

\section{3 イオン衝撃パラメータ $\boldsymbol{P}_{\mathrm{i}}$}

イオン衝撃パラメータ $P_{\mathrm{i}}$ は, イオンと堆積粒子の入射頻 度の比を表す $i / a$ の項とイオン 1 個あたりの運動量の大きさ を表す $|p|$ の項の積によって定義される.

$$
P_{\mathrm{i}}=\left(\frac{i}{a}\right)|p|
$$

ラングミュアプローブ法により得られた電流電圧特性の変 曲点付近の傾き $d l n I_{\mathrm{e}} / d V$ から求められた電子温度 $T_{\mathrm{e}}(\mathrm{eV})$ と $V_{\mathrm{s}}$ におけるイオンの電子電流密度 $I_{\mathrm{e} 0}$ より, 電子密度 $N_{e}$ を次式より算出した.

$$
N_{e}=3.73 \times 10^{13} \frac{I_{\mathrm{e} 0}}{\sqrt{T_{\mathrm{e}}}}
$$

プラズマが熱平衡と仮定すると, イオンと電子は同数存在 するので，イオンの数密度 $N_{\mathrm{i}}\left(\mathrm{m}^{-3}\right)$ は $N_{e} \approx N_{\mathrm{i}}$ となる. イオ ンの入射頻度 $i\left(\mathrm{~m}^{-2} \cdot \mathrm{s}^{-1}\right)$ は, 入射する $N_{\mathrm{i}}$ と $\bar{v}_{\mathrm{i}}$ を用いて次式 より算出される.

$$
i=N_{\mathrm{i}} \bar{v}_{\mathrm{i}}
$$

堆積粒子の入射頻度 $a\left(\mathrm{~m}^{-2} \cdot \mathrm{s}^{-1}\right)$ は，堆積膜の密度はバル ク密度と同等であると仮定し，ターゲットである $\mathrm{Ni}$ の密度 $\rho_{\mathrm{Ni}}\left(\mathrm{kg} \cdot \mathrm{m}^{-3}\right)$, 薄膜の堆積速度 $r_{\mathrm{d}}\left(\mathrm{m} \cdot \mathrm{s}^{-1}\right), \mathrm{Ni} の$ モル質量 $M_{\mathrm{Ni}}\left(\mathrm{kg} \cdot \mathrm{mol}^{-1}\right)$ を用いて次式から導出される.

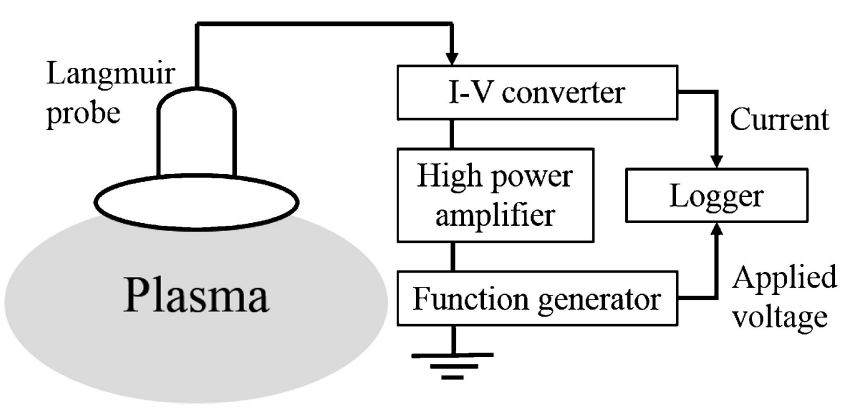

Fig. 2 Schematic diagram of Langmuir probe. 


$$
a=\frac{r_{\mathrm{d}} \rho_{\mathrm{Ni}}}{M_{\mathrm{Ni}}}
$$

イオン 1 個あたりの運動量の大きさ $|p|$ は, イオンの質量 $m_{\mathrm{i}}(\mathrm{kg})$, 基板に入射するイオンの速度 $v_{\mathrm{i}}\left(\mathrm{m} \cdot \mathrm{s}^{-1}\right)$ を用いて次 式から導出される.

$$
|p|=m_{\mathrm{i}} \cdot v_{\mathrm{i}}
$$

\section{4 内部応力の測定}

光てこ法により短冊状の $(4.7 \mathrm{~mm} \times 24.7 \mathrm{~mm} \times 0.3 \mathrm{~mm})$ の $\mathrm{Si}$ ウェ八基板に成膜した試料の長手方向の反りを求め，薄 膜の内部応力により生じた試料の曲率半径を計算した。レー ザーと位置検出素子を含む, 光路長 $1.3 \mathrm{~m}$ のシングルビーム 光学系から構成される薄膜応力測定装置において, オプティ カルフラットとしての成膜前の基板と成膜後の試料の反射光 の位置変化により，薄膜堆積前後の基板の曲率半径の変化を 求めた. 薄膜の内部応力 $\sigma(\mathrm{GPa})$ は基板の反りの曲率半径 $R$ と基板に用いた $\mathrm{Si}(100)$ のング率 $Y_{\mathrm{s}}$, ポアソン比 $v_{\mathrm{s}}$, 基 板厚 $t_{\mathrm{s}}$, 膜厚 $t_{\mathrm{f}}$ を用いて以下の Stoneyの式(1) より求めた.

$$
\sigma=\frac{Y_{\mathrm{s}} t_{\mathrm{s}}^{2}}{6\left(1-v_{\mathrm{s}}\right) R t_{\mathrm{f}}}
$$

\section{3. 結果および考察}

Fig. 3 に基板バイアス $V_{\text {sub }}$ と成膜中の基板に入射するイ オンと堆積粒子の入射頻度比 $i / a$ を示す． $V_{\text {sub }}$ を深くするの に従い， $i / a$ はスパッタリングガスに $\mathrm{Ar}$ を用いた時と Xe を用いた時の双方に扔いて増加を示した。加えて，i/aはス パッタリングガスに Xe を用いた時よりも Ar を用いた時の 方が大きくなった。本実験ではスパッタ電力を一定で行って いるため, 堆積粒子の入射頻度 $a$ は変化しない，このことか ら，i/aの増加はイオンの入射頻度 $i$ が増加したことに起因 している，基板バイアスを深くするに伴い， $V_{\mathrm{s}}$ と $V_{\mathrm{sub}}$ の電 位差によって加速されたイオンの $v_{\mathrm{sh}}$ が増加したため $i$ が増 加したと考えられる。 また，各スパッタリングガスが $V_{\mathrm{s}}$ と

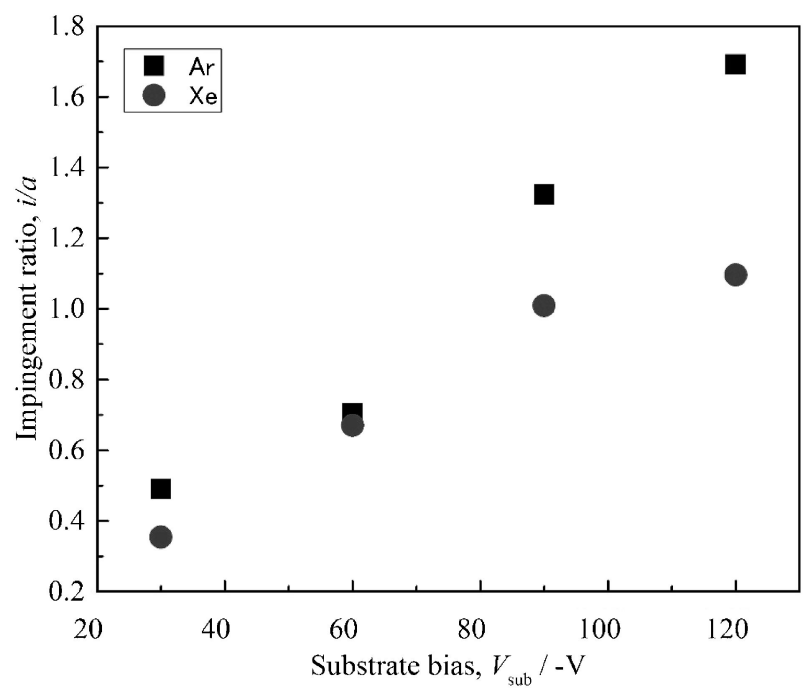

Fig. 3 Impingement ratio $i / a$ as a function of substrate bias $V_{\text {sub. }}$.
$V_{\mathrm{sub}}$ で与えられる電位差は一定であるが，Xe に比べ Ar は 質量が小さいため $v_{\mathrm{sh}}$ が大きくなった。このことから，Xe に比べ Arを用いた時に $i / a$ が大きくなったと考えられる.

Fig. 4 に基板バイアス $V_{\text {sub }}$ に対するイオンの運動量 $|p|$ の 変化を示す． $V_{\text {sub }}$ を深くするのに従い， Arイオンと Xeイ オンの $|p|$ はどちらも増加を示した．これは $V_{\text {sub }}$ を深くする ことによって $v_{\mathrm{i}}$ が大きくなり $|p|$ が増加を示したと考えられ る。基板に入射するイオンの速度 $v_{\mathrm{i}}$ は先ほども述べたよう に，質量の小さい Arのほうが大きい。しかし，スパッタリ ングガスの質量は $\mathrm{Ar} よ り も \mathrm{Xe}$ のほうが約 3 倍と大きいた め, 運動量のパラメータの変化としてはスパッタリングガス の質量に依存し, Xeイオンの $|p|$ が大きくなったと考えら れる。

Fig. 5 に基板バイアス $V_{\text {sub }}$ に対する作製した薄膜の内部 応力 $\sigma$ を示す. 図の縦軸正の值は作製した薄膜の引張応力 を示し負の值は圧縮応力を示す。いずれのスパッタリングガ 久種において， $V_{\text {sub }}$ を深くするのに従い $\sigma$ は減少し，引張 応力から圧縮応力へと変化した．成膜条件の熱応力は一定て

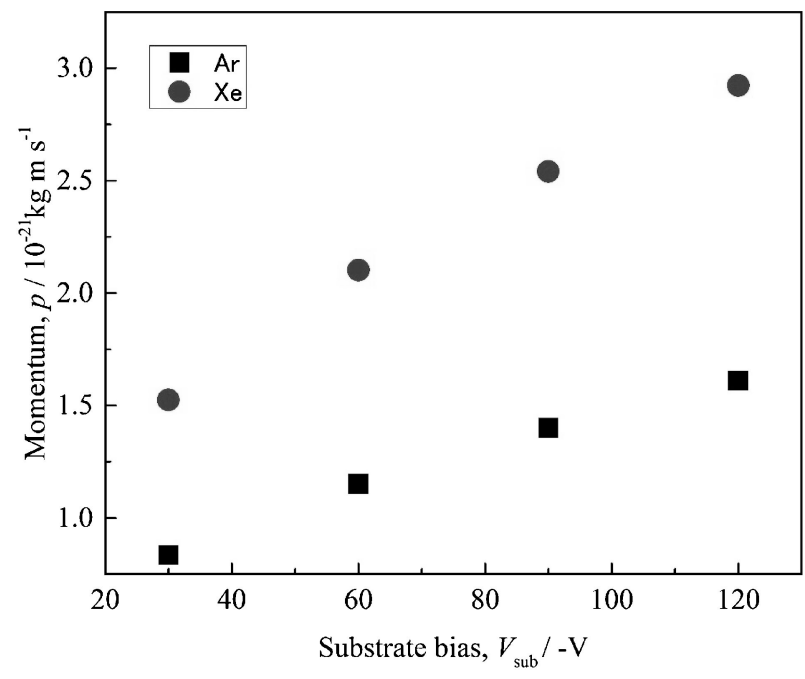

Fig. 4 Momentum $p$ as a function of substrate bias $V_{\text {sub }}$.

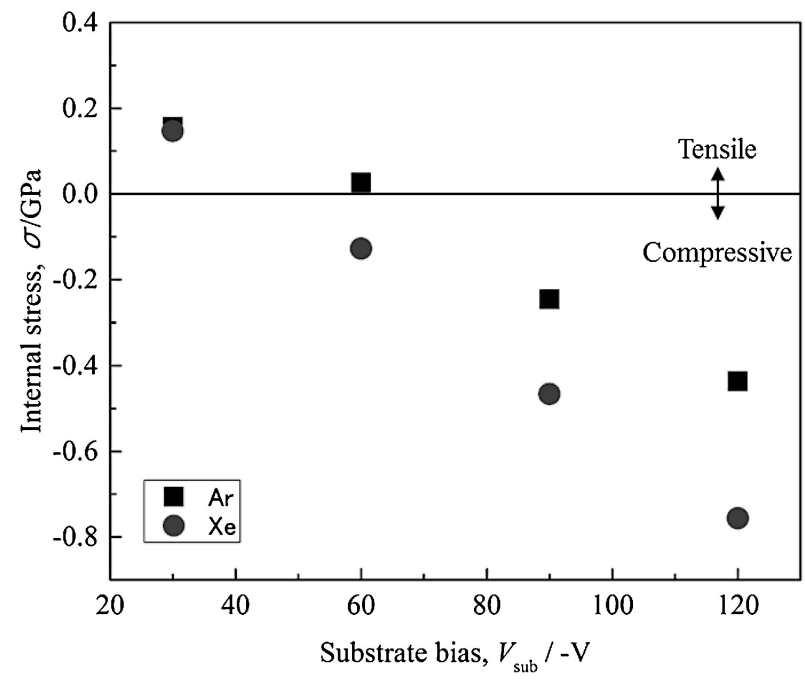

Fig. 5 Internal stress $\sigma$ as a function of substrate bias $V_{\text {sub. }}$. 
あるため， $V_{\text {sub }}$ を深くすることによりイオンの $|p|$ と $i か ゙$ 増 加することから, 圧縮応力発生させるピーニング効果が増加 し, 薄膜の内部応力は引張応力から圧縮応力に変化したと考 えられる. また，Fig. 4 で示したように，基板バイアス $V_{\text {sub }}$ に対して基板に入射するイオンの $|p|$ が Arに比べ，Xeの変 化が大きいことでピーニング効果の影響が大きくなり，応力 の変化が大きくなったと考えられる.

Fig. 6 はイオン衝撃パラメータ $P_{\mathrm{i}}$ に対する薄膜の内部応 力 $\sigma$ の変化を示す. Fig. 5 と同様に図の縦軸正の值は作製 した薄膜の引張応力を示し，負の值は圧縮応力を示す．基板 バイアス $V_{\text {sub }}$ を深くするに従い，いずれのスパッタリング ガスに掠てもイオン衝撃パラメータ $P_{\mathrm{i}}$ は増加とともに, 薄膜の内部応力は引張応力から圧縮応力へと変化した. $P_{\mathrm{i}}$ に対する応力の変化量は Ar に比べ Xe のほうが僅かに大き くなった，また， $P_{\mathrm{i}}$ に対する内部応力の変化は $\mathrm{Ar}, \mathrm{Xe} の$ どちらも直線的に变化し, 同一線上に乗ることがわかった. これにより，スパッタリングガスの種類にかかわらず，イオ ン衝撃パラメータ $P_{\mathrm{i}}$ を用いることにより，薄膜の内部応力 を定量的に評価することができ，目的に応じた応力を持つ薄 膜の作製が容易に行えると考えられる.

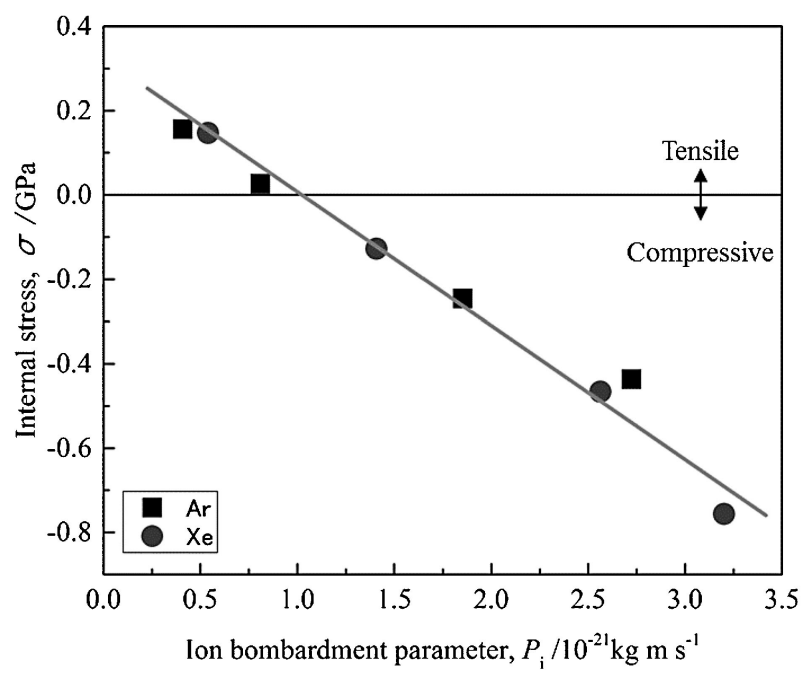

Fig. 6 Internal stress $\sigma$ as a function of ion bombardment parameter $P_{\mathrm{i}}$.

\section{4. 結言}

本研究では原子量の異なるスパッタリングガス環境下で, 基板バイアスを変化させ成膜を行った．また，ラングミュア プローブとマルチグリッド型静電イオンアナライザーを用い てプラズマ診断を行い，イオン衝撃パラメータ $P_{\mathrm{i}}$ を用いて 薄膜作製時に生じる内部応力に与えるイオン衝撃の影響を評 価した．基板バイアスを深くするに従い，イオンの質量が小 さいほど入射速度および入射頻度が増加し，イオンの質量が 大きいほど運動量が増加した．イオン衝撃パラメータ $P_{\mathrm{i}}$ と しては，質量の大きいXeの方が $\mathrm{Ar} に$ 比べ大きくなった. これにより，薄膜に与えるピーニング効果が増加し，薄膜の 内部応力は引張応力から压縮応力へ変化した. 薄膜の内部応 力の変化はイオン衝撃パラメータ $P_{\mathrm{i}}$ を用いることにより, 定量的に評価することができ, 薄膜の内部応力を自由に制御 できると考えられる.

本研究は東海大学未来科学技術共同研究センターのエネル ギー材料創生プロセスに関する研究において遂行された。こ こに感謝の意を示す. 本研究は平成 25 年度科学研究費補助 金基板研究 $(\mathrm{C})$ (課題番号 24560859)により行われた.

文献

1) D. W. Hoffman and M. R. Gaerttner: J. Vac. Sci. Technol. 17 (1980) 425-428

2) T. J. Vink and J. B. A. D. Van Zon: J. Vac. Sci. Technol. A 9 (1991) 124-127.

3) F. Schatz, M. Hirscher and M. Schnell: J. Appl. Phys. 76 (1994) $5380-5382$

4) R. Wolfe and J. C. North: J. Vac. Sci. Technol. 15(1978) 16751684.

5) A. Misra, S. Fayeulle, H. Kung, T. E. Mitchel and M. Nastasi: Nucl. Instr. and Meth. in Phys. Res. B 148(1999) 211-215.

6) S. G. Mayr and R. S. Averback: Phys. Rev. B 68(2003) 2141051-21410510.

7) H. Windishmann: J. Appl. Phys. 62 (1987) 1800-1807.

8) C. K. Hwangbo, L. J. Lingg, J. P. Lehan, H. A. Macleod, J. L. Makous and S. Y. Kim: Appl. Opt. 28 (1989) 2769-2778.

9) G. Carter: J. Phys. D: Appl. Phys. 27 (1994) 1046-1055.

10) N. Satomi, K. Tanaka, M. Kitamura and M. Nishikawa: J. Nucl. Mater. 241-243 (1997) 1138-1141.

11) D. W. Hoffman and M. R. Gaerttner: J. Vac. Sci. Technol. 17 (1980) 425-428.

12) R. Toyoda, S. Toya, M. Hashimoto, A. Kohri and Y. Matsumura: J. Japan Inst. Met. Mater. 78(2014) 132-136.

13) M. Yamashita: J. Vac. Soc. Japan. 26 (1983) 507-510.

14) G. G. Stoney: Proc. R. Soc. London. A 82(1909) 172-175. 